\title{
Reversal of Metabolic Dysfunction through Polyvalent Pharmacotherapy- augmented Lifestyle Intervention: Case Reports
}

\author{
Ong YC ${ }^{1 *}$, Su $\mathrm{LH}^{1}$ and Zaini $\mathrm{A}^{2}$
}

${ }^{1}$ Metabolic Health Programme, Centre for Integrative Weight-Healthcare, Vivo Health LLP, Singapore

2Jeffrey Cheah School of Medicine and Health Sciences, Monash University, Sunway Campus, Malaysia

\begin{abstract}
The natural history of the metabolic syndrome is marked by progression from endocrine and metabolic perturbations to overt diabetes, hypertension, secondary complications of nephropathy, neuropathy and retinopathy; along with serious comorbidities such as vascular disorders and cancers of the colon, breast, ovary and prostate gland. Here, we report four case studies involving patients with suboptimal control of metabolic factors treated with an integrated regimen of lipid-modifying agents, pleiotropic botanical medicine and lifestyle intervention. Over the course of 7 to 13 months, striking improvements to the triad of fasting plasma glucose, blood pressure, lipid profile were observed; with concomitant stabilisation of the body mass index and body fat percentage.

Our results proffer early clinical evidence that hormonal and metabolic competency can be restored, and progression of the metabolic syndrome arrested, through use of polyvalent pharmacotherapy to enable less intrusive lifestyle changes - without requiring significant weight loss which notably, conferred more effective and sustained control over the constellation of lipemia, glycemia, arterial tension, atherogenicity and adipo-obesity.
\end{abstract}

Keywords: Polyvalent botanical medicine; Augmented lifestyle intervention; Metabolic syndrome; Glucose transporters; Androgen receptor; Peroxisome proliferator-activated receptors; Gastrointestinal enzymes

\section{Introduction}

A recent WHO bulletin report across seven countries, revealed patients attaining treatment targets for blood glucose, arterial blood pressure and serum cholesterol to be extremely low, ranging from $1 \%$ in Mexico to $12 \%$ in the United States [1]. At the same time, the long term consequences of poorly controlled diabetes, hypertension and obesity are alarming - serious morbidities and high mortality rate [2-4].

Therefore, there is an urgent need to innovate new approaches that will sustainably stabilise the metabolic syndrome, or to an even greater extent, restore metabolic health; preferably, without requiring severe lifestyle curtailment and escalating doses of pharmacotherapeutic agents. Imposing strict behavior, dietary and exercise regimens, or the progressive failure to reach treatment goals necessitating dose escalation, polypharmacy and parenteral interventions generally have an adverse impact on lifelong patient compliance. This is compounded by the elevated risks of adverse drug reactions and iatrogenic endorgan damage associated with heavy medication load.

Previously, we reported the reversal of hyperglycemia and reduced medication load in a patient with 15-year history of type 2 diabetes mellitus and the metabolic syndrome, through an integrated model of medical care and weight-healthcare [5]. The latter refers to clinical diagnosis and management with prescribed medications (listed in the Drug Schedules) combined with sustainable tripartite weight management involving botanical medicines (listed in the Monthly Index of Medical Specialties [MIMS] and/or regulated under the Medicines Act), dietary (main meals) changes, behaviorietary (recreational food and drinks with negligible calorie content) substitutes and mild physical activity.

At the same time, our earlier clinical work had also demonstrated that directed pharmacotherapy at the molecular level, through the androgen receptor (AR), can translate into phenotypic response at the clinical level [6]. The AR belongs to the same superfamily of transcription factors as the peroxisome proliferator-activated receptors (PPARs), both of which are pharmacologic targets in this study. The other functional proteomic targets include $\mathrm{Na}^{+}$-coupled glucose transporters (SGLT), facilitative glucose transporters (GLUT), gastrointestinal disaccharidases and lipases.

Here, we present four case studies that extend the therapeutic effects of the integrative treatment model to the entire metabolic milieu.

\section{Case Report 1}

Male patient aged 68 y.o. with 10-year history of progressive obesity and the metabolic syndrome. Dyslipidemia and hypertension management - simvastatin (40 mg q.d.) and atenolol (25 mg q.d.). At baseline (Visit 0): body mass index $(\mathrm{BMI})=25.4 \mathrm{~kg} / \mathrm{m}^{2}$, blood pressure $(\mathrm{BP})=114 / 66 \mathrm{mmHg}$, waist-to-hip ratio $(\mathrm{WHR})=0.94$, body fat $(\mathrm{BF})$ $=28 \%$.

The patient was on combined 3-hydroxy-3-methylglutaryl coenzyme A (HMG-CoA) reductase inhibitor and beta-blocker treatment with suboptimal control of dyslipidemia. Existing low intensity lifestyle intervention consisted of $30 \mathrm{~min}$ stroll at least five days a week, and a balanced diet (WHO food pyramid). Behaviorietary (negligible calorie) sweetener and fruit juice substitutes for ad libitum daily use were introduced at Visit 0 , along with AR-augmenting phytoandrogens (Enerbolis, 1000mg b.i.d.), dietary supplements of

${ }^{*}$ Corresponding author: Dr. Ong YC, Metabolic Health Programme, Centre fo Integrative Weight-Healthcare, North Bridge Centre, 420 North Bridge Road \#03-11, Singapore 188727, Tel: +65 63383385; Fax: +65 63383381; E-mail: ongyekcheng@gmail.com

Received May 26, 2011; Accepted July 21, 2011; Published July 25, 2011

Citation: Ong YC, Su LH, Zaini A (2011) Reversal of Metabolic Dysfunction through Polyvalent Pharmacotherapy-augmented Lifestyle Intervention: Case Reports. J Diabetes Metab 2:133. doi:10.4172/2155-6156.1000133

Copyright: ( 2011 Ong YC, et al. This is an open-access article distributed unde the terms of the Creative Commons Attribution License, which permits unrestricted use, distribution, and reproduction in any medium, provided the original author and source are credited. 
lyophilised vegetables (Tri-phyll, $10 \mathrm{~g}$ and Protecmin, $13 \mathrm{~g}$ ) and protein complex (ProMDR100, 30g), thrice weekly [7].

These additional lifestyle changes were accompanied by adjuvant treatment with a proprietary botanical complex providing gymnemic acids $\geq 25 \mathrm{mg} / \mathrm{g}$, charantin $\geq 10 \mathrm{mg} / \mathrm{g}$, phytosterols, beta-ursolic acid, carnosol, carnosic acid and rosmarinic acid (ES-Triguard, $1000 \mathrm{mg}$ t.i.d), characterised by pleiotropic mechanisms of action (GLUT4, PPARa, PPAR $\gamma$ upregulators and GLUT2, SGLT, disaccharidase, lipase inhibitors).

After 13-month interval (Visit 5): BMI $=25 \mathrm{~kg} / \mathrm{m}^{2}, \mathrm{BP}=120 / 72$ $\mathrm{mmHg}, \mathrm{WHR}=0.91, \mathrm{BF}=26 \%$. Normal lipid profile was restored $(\mathrm{TC}$ $<200 \mathrm{mg} / \mathrm{dL}$; LDL-C < $130 \mathrm{mg} / \mathrm{dL}$; HDL-C > $38 \mathrm{mg} / \mathrm{dL}$; TG < $200 \mathrm{mg} /$ $\mathrm{dL}$ ) (Table 1). Anti-atherosclerotic indicator TC/HDL-C ratio was also normalised, from 5 (Visit 0 ) to 3.4 (Visit 5) (ref range $\leq 4$ ); BP retained optimal control (114/66 mmHg \& $120 / 72 \mathrm{mmHg}$ respectively) with concomitant stabilisation of BMI (from $25.4 \mathrm{~kg} / \mathrm{m}^{2}$ to $25 \mathrm{~kg} / \mathrm{m}^{2}$ ) and BF (from $28 \%$ to $26 \%$ ) (Figure 2).

\section{Case Report 2}

Male patient aged 45 y.o. with recent history of heavy alcohol use, high fat diet, weight gain and hyperphagia (in part, due to nicotine withdrawal). Dyslipidemia management - lovastatin (20 mg q.d.) and fenofibrate (300 mg q.d.). At baseline (Visit 0): BMI $=28.1 \mathrm{~kg} / \mathrm{m}^{2}, \mathrm{BP}$ $=122 / 85 \mathrm{mmHg}, \mathrm{WHR}=1, \mathrm{BF}=34 \%$, fasting plasma glucose $(\mathrm{FPG})$ $=97.2 \mathrm{mg} / \mathrm{dL}$.

Patient had suboptimal control of dyslipidemia, complicated by poor lifestyle habits and nicotine withdrawal. Existing physical activity consisted of $30 \mathrm{~min}$ jog 1-2 times weekly with once-weekly weights training. Additional lifestyle intervention was attempted, but patient compliance was low. Behaviorietary use of alcohol continued unabated. Daily dietary intake of cholesterol-rich seafood (in addition to fish) remained high. However, red meat intake was reduced to less than 3 times weekly.

After 7-month interval (Visit 8): BMI $=28.1 \mathrm{~kg} / \mathrm{m}^{2}, \mathrm{BP}=119 / 80$ $\mathrm{mmHg}, \mathrm{WHR}=1, \mathrm{BF}=28 \%, \mathrm{FPG}=92 \mathrm{mg} / \mathrm{dL}$. Augmentation of existing statin (20 mg q.d.) and fibrate (300 mg q.d.) combination therapy, with ES-Triguard (1000 mg t.i.d.) over 7 months aided lipid

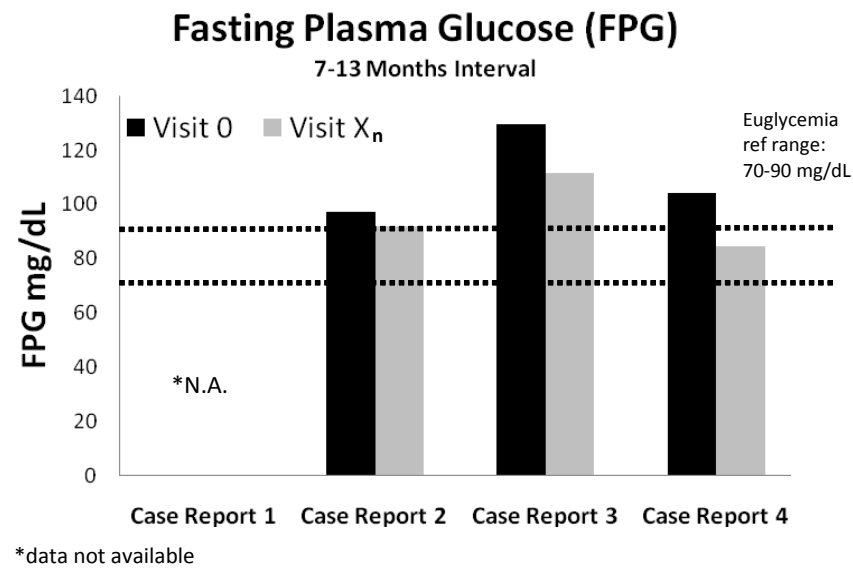

Figure 1: Glycemic control of patients with the metabolic syndrome, evaluated with fasting plasma glucose $(\mathrm{mg} / \mathrm{dL})$. Visit $X_{n}$ for case reports 1-4: Visit 5 (13 months interval), Visit 8 (7 months interval), Visit 16 (11 months interval) and Visit 15 (12 months interval) respectively.

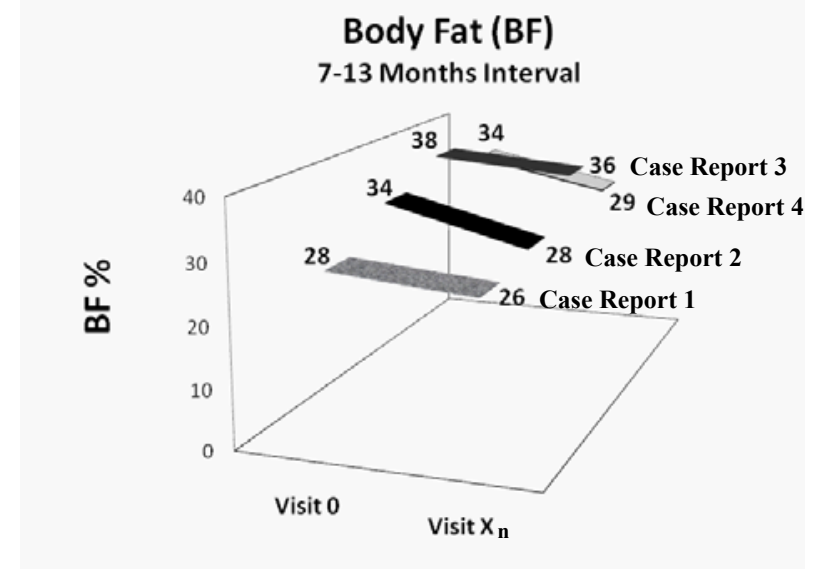

Figure 2: Adiposity control in patients with the metabolic syndrome, measured using body fat (\%). Visit $X$ for case reports 1-4: Visit 5 (13 months interval), Visit 8 (7 months interval), Visit 16 (11 months interval) and Visit 15 (12 months interval) respectively.

control albeit treatment targets for lipemia remained unmet (Table 1). Anti-atherosclerotic indicator TC/HDL-C ratio was reduced from 6.5 (Visit 0) to 5.6 (Visit 8) (ref range $\leq 4$ ). Of notable interest, other factors in the metabolic cluster improved significantly - BP from $122 / 85 \mathrm{mmHg}$ (pre-hypertensive) to $119 / 80 \mathrm{mmHg}$ (normotensive); FPG from $97.2 \mathrm{mg} / \mathrm{dL}$ to $92 \mathrm{mg} / \mathrm{dL}$ (euglycemia ref range $70-90 \mathrm{mg} /$ $\mathrm{dL}$ ), with complete arrest of spiraling weight (BMI stabilisation) and an anti-adiposity effect (BF $34 \%$ to 28\%) (Figure 1, Figure 2).

\section{Case Report 3}

Female patient aged 43 y.o. with 20 -year history of creeping weight (postnatal); presenting with the metabolic syndrome (obesity, adiposity, hypertension, dyslipidemia and transitional [early] type 2 diabetes). Hypertension and dyslipidemia under treatment, with losartan (25 mg q.d.) and simvastatin (half-tab, $10 \mathrm{mg}$ q.d.). Patient had delayed oral anti-diabetic drug (OAD) initiation by her attending physician. At baseline (Visit 0): $\mathrm{BMI}=27.5 \mathrm{~kg} / \mathrm{m}^{2}, \mathrm{BP}=118 / 80 \mathrm{mmHg}$, $\mathrm{WHR}=0.85, \mathrm{BF}=38 \%, \mathrm{FPG}=129.6 \mathrm{mg} / \mathrm{dL}$, glycated hemoglobin A1c $\left(\mathrm{HbA}_{1 \mathrm{c}}\right)=7.1 \%$.

Low intensity lifestyle intervention was introduced - existing carbohydrate and fat-rich diet was modified with complex protein and lyophilised vegetables supplements. Daily $30 \mathrm{~min}$ pacing at home was initiated. These non-intrusive changes were augmented with polyvalent pharmacotherapy comprising of existing statin (10 mg q.d.) and losartan (25 mg q.d.) combination therapy, with the introduction of ES-Triguard (1000 mg b.i.d.)

After 11-month interval (Visit 16): BMI $=26.4 \mathrm{~kg} / \mathrm{m}^{2}, \mathrm{BP}=109 / 72$ $\mathrm{mmHg}, \mathrm{WHR}=0.84, \mathrm{BF}=36 \%, \mathrm{FPG}=111.6 \mathrm{mg} / \mathrm{dL}, \mathrm{HbA}_{1 \mathrm{c}}=6.6 \%$. Significantly restored metabolic competency can be observed. For instance, the lipid profile had been completely normalised (Table 1). Anti-atherosclerotic indicator TC/HDL-C ratio was lowered from 4.5 (Visit 0) to 3.6 (Visit 16) (ref range $\leq 4$ ); tighter glycemic and adipoobesity controls were also achieved - FPG from $129.6 \mathrm{mg} / \mathrm{dL}$ (diabetic) to $111.6 \mathrm{mg} / \mathrm{dL}$ (non-diabetic), with $\mathrm{HbA}_{1 \mathrm{c}}$ declining from $7.1 \%$ (pathological glycation level) to $6.6 \%$ (borderline glycation level, ref range $<6.5 \%$ ); reversal of creeping weight (BF from $38 \%$ to $36 \%$, BMI from $27.5 \mathrm{~kg} / \mathrm{m}^{2}$ to $26.4 \mathrm{~kg} / \mathrm{m}^{2}$ ) (Figure 2). 
Citation: Ong YC, Su LH, Zaini A (2011) Reversal of Metabolic Dysfunction through Polyvalent Pharmacotherapy-augmented Lifestyle Intervention: Case Reports. J Diabetes Metab 2:133. doi:10.4172/2155-6156.1000133

\begin{tabular}{|l|l|l|l|l|}
\hline \multicolumn{5}{|l|}{ Lipid profile and atherosclerotic index (TC/HDL-C ratio) } \\
\hline & $\begin{array}{l}\text { Case } \\
\text { Report 1 }\end{array}$ & $\begin{array}{l}\text { Case } \\
\text { Report 2 }\end{array}$ & $\begin{array}{l}\text { Case } \\
\text { Report 3 }\end{array}$ & $\begin{array}{l}\text { Case } \\
\text { Report 4 }\end{array}$ \\
\hline Visit 0 & 243.2 & 280 & 204 & 255.5 \\
\hline TC (mg/dL) & 160.9 & $-^{*}$ & 138 & 177.5 \\
\hline LDL-C (mg/dL) & 49.1 & 43 & 45 & 56.6 \\
\hline HDL-C (mg/dL) & 167.4 & 500 & 102 & 107.2 \\
\hline TG (mg/dL) & 5 & 6.5 & 4.5 & 4.5 \\
\hline TC/HDL-C ratio & & & & \\
\hline Visit X & 190.6 & 229 & 185 & 247.8 \\
\hline TC (mg/dL) & 112.9 & $-^{*}$ & 120 & 169.1 \\
\hline LDL-C (mg/dL) & 55.7 & $\mathbf{4 1}$ & $\mathbf{5 2}$ & $\mathbf{6 3 . 3}$ \\
\hline HDL-C (mg/dL) & 111.6 & 611 & 66 & 77.1 \\
\hline TG (mg/dL) & 3.4 & $\mathbf{5 . 6}$ & 3.6 & 3.9 \\
\hline TC/HDL-C ratio & & & & \\
\hline & & & & \\
\hline
\end{tabular}

*Out of range due to hypertriglyceridemia

Table 1: Laboratory data on cholesterols and triglycerides at baseline (Visit 0 ) and post-treatment $\left(\right.$ Visit $X_{n}$ ). Case report 1, $n=5$ (13 months interval); Case report 2, $n$ $=8$ (7 months interval); Case report $3, n=16$ (11 months interval); Case report $4, n$ $=15$ (12 months interval). Atherosclerotic index values are shaded grey.

\section{Case Report 4}

Female patient aged 52 y.o. Postmenopausal, with history of fibromyalgia and gastritis. At baseline (Visit 0 ): $\mathrm{BMI}=23 \mathrm{~kg} / \mathrm{m}^{2}, \mathrm{BP}=$ $108 / 76 \mathrm{mmHg}, \mathrm{WHR}=0.87, \mathrm{BF}=34 \%, \mathrm{FPG}=104.4 \mathrm{mg} / \mathrm{dL}$.

Simple lifestyle changes were carried out by the patient, which comprised of daily AR-augmenting phytoandrogens, protein complex and vegetables supplementation, coupled to $30 \mathrm{~min}$ stroll on a treadmill 1-2 times weekly. Daily use of zero calorie natural sweetener and fruit juice behaviorietary substitute were unrestricted i.e. ad libitum. This extremely low key lifestyle intervention was augmented with ESTriguard (1000 mg b.i.d.) monotherapy over 12 months.

After 12-month interval (Visit 15): $\mathrm{BMI}=21 \mathrm{~kg} / \mathrm{m}^{2}, \mathrm{BP}=107 / 78$ $\mathrm{mmHg}, \mathrm{WHR}=0.82, \mathrm{BF}=29 \%, \mathrm{FPG}=84.6 \mathrm{mg} / \mathrm{dL}$. The combined interventions led to marked improvements in the patient's lipid profile i.e. reduced levels of TC, LDL-C, TG and increased HDL-C value (Table 1). Anti-atherosclerotic indicator TC/HDL-C ratio was normalised, from 4.5 (Visit 0) to 3.9 (Visit 15) (ref range $\leq 4$ ). Notably, other metabolic factors such as FPG and adiposity were also normalised concurrently - FPG from $104.4 \mathrm{mg} / \mathrm{dL}$ (pre-diabetic) to $84.6 \mathrm{mg} / \mathrm{dL}$ (euglycemic); BF from 34\% (high adiposity) to $29 \%$ (within recommended range for age and gender) (Figure 1, Figure 2).

\section{Discussion}

Chronic perturbations to energy metabolism (transport, breakdown, release and utilisation of sugars, fatty acids and amino acids) drive pathological molecular and cellular events - supraphysiological glycation, oxidation stress and chronic inflammation - and adversely affect systemic homeostasis (such as euglycemia and normotension). Inevitably, dysfunctions of the metabolic pathways result in progressive tissue and end-organ damage.

Unfortunately, besides pharmacotherapy, bariatric lifestyle intervention of the metabolic syndrome tend to focus on the modulation of daily energy intake and expenditure (energy flux) through calorie restriction and brisk exercise; the objective being weight (BMI) reduction and associated endocrine/metabolic benefits.

On the other hand, therapies directed at aspects of energy metabolism and energy distribution (fat deposits [adipose tissue] versus protein deposits [muscle tissue]), over and beyond energy

flux, have the potential to provide significant adjuvant effects on long term management of type 2 diabetes, hypertension and other cardio- and cerebrovascular risk factors. Importantly, adipose tissues are adipokine-secreting, while muscle tissues aid peripheral glucose disposal i.e. energy and endocrine functions are cross-linked and can contribute to metabolic competency.

The four case studies presented here provide strong clinical evidence that supports the treatment strategy of energy tri-modulation (flux, distribution and metabolism).The positive results are myriad a) tighter control of clinical endpoints, b) tapering of drug count and dosage, c) comparatively less restrictive behaviour modification and greater patient adherence to treatment program over time.

For instance, elevated FPG levels in case reports 2-4 at baseline showed euglycemic reversion (euglycemia ref range $70-90 \mathrm{mg} / \mathrm{dL}$ ) over the course of 7-13 months: $97.2 \mathrm{mg} / \mathrm{dL}$ (Visit 0) to $92 \mathrm{mg} / \mathrm{dL}$ (Visit 8), $129.6 \mathrm{mg} / \mathrm{dL}$ (Visit 0) to $111.6 \mathrm{mg} / \mathrm{dL}$ (Visit 16), $104.4 \mathrm{mg} / \mathrm{dL}$ (Visit 0 ) to $84.6 \mathrm{mg} / \mathrm{dL}$ (Visit 15) respectively (Figure 1). In case report 3, normalising FBG translated to significantly improved $\mathrm{HbA}_{1 c}$ levels, from pathological to near-physiological glycosylation levels (American Diabetes Association [ADA] reference range <6.5\%): $\mathrm{HbA}_{1 \mathrm{c}}=7.1 \%$ (Visit 0) to $\mathrm{HbA}_{1 \mathrm{c}}=6.6 \%$ (Visit 16)

The optimisation of glycemic control in these patients correlated to normalising serum cholesterol levels, reduced atherogenicity (TC/ HDL-C ratio $\leq 4$ ), total arrest of creeping adipo-obesity (BF reduction $\geq 2 \%$, BMI increment $\leq 0 \mathrm{~kg} / \mathrm{m}^{2}$ ) and well-controlled arterial blood pressure $(\leq 120 / 80 \mathrm{mmHg}$ for all four case studies); without the involvement of strenuous exercise, increased drug load or significant weight loss (Table 1, Figure 2).

Notwithstanding the small numbers of subjects, the outcome of this study suggests that stabilising the body weight (energy flux equilibrium) over an extended period of time is sufficient to support the restoration of metabolic health, and conversely, antagonise progression of the metabolic syndrome. The caveat being, key mediators of energy metabolic pathways (e.g. PPARa, PPAR $\gamma$, AR, GLUT2, GLUT4, SGLT, lipase, disaccharidase, HMG-CoA reductase) and fat energy distribution (adiposity), which influences the endocrine-metabolism axis, must also be modulated concomitantly. Clinically, this is possible through a combined regimen of polyvalent pharmacological intervention and sustainable, discreet lifestyle changes.

In conclusion, these case reports present early clinical evidence for our treatment strategy of energy tri-modulation (using integrative therapies), in advancing best standard-of-care for the metabolic syndrome. A 5-year longitudinal cohort study $(\mathrm{N}=51)$ with age, sex and BMI matched subjects is ongoing (currently into the second year), which should further consolidate the clinical evidence that the novel approach described here is sustainable and effective.

\section{Acknowledgements}

Outpatient medical treatments were provided by the following entities National Heart Centre (case report 1), Dayspring Medical Clinic; Central Clinic \& Surgery (case report 2), Dayspring Medical Clinic (case report 3), Shenton Medical Group Clinics (case report 4). Diagnostic laboratory services were provided by - National Heart Centre Central Laboratory (case report 1), Quest Laboratories; Pathology \& Clinical Laboratory (case reports 2 and 3), Parkway Health Laboratory (case report 4).

\section{References}

1. Gakidou E, Mallinger L, Abbott-Klafter J, Guerrero R, Villalpando S (2011) Management of diabetes and associated cardiovascular risk factors in seven countries: a comparison of data from national health examination surveys. Bull World Health Organ 89: 172-183. 
Citation: Ong YC, Su LH, Zaini A (2011) Reversal of Metabolic Dysfunction through Polyvalent Pharmacotherapy-augmented Lifestyle Intervention: Case Reports. J Diabetes Metab 2:133. doi:10.4172/2155-6156.1000133

2. Song M, Alexander CM, Mavros P, Lopez VA, Malik S, et al. (2011) Use of the UKPDS outcomes model to predict all-cause mortality in U.S. adults with type 2 diabetes mellitus: comparison of predicted versus observed mortality. Diabetes Res Clin Pract 91: 121-126.

3. Bray GA, Bellanger T (2006) Epidemiology, trends, and morbidities of obesity and the metabolic syndrome. Endocrine 29: 109-117.

4. Chen G, McAlister FA, Walker RL, Hemmelgarn BR, Campbell NR (2011) Cardiovascular outcomes in Framingham participants with diabetes: the importance of blood pressure. Hypertension 57: 891-897.
5. Victor Ong YC, Nicole Su LH, Benny Tan KH (2009) Sustainable tripartite weight management: case report of euglycaemic reversion in type 2 diabetes with 15-year history. AFIHT Euro J Nutr \& Fn Fd 20: 43-45.

6. Ong YC, Wong HB, Adaikan G, Yong EL (1999) Directed pharmacologica therapy of ambiguous genitalia due to an androgen receptor gene mutation. Lancet 354: 1444-1445.

7. Ong VY, Tan BK (2007) Novel phytoandrogens and lipidic augmenters from Eucommia ulmoides. BMC Complement Altern Med 7: 3 . 